\title{
Automated Schedule Monitoring System for Precast Building Construction Using Enhanced - Geographic Information System (GIS)
}

\author{
Min-Yuan Cheng ${ }^{1}$ and Jiann-Chyun Chen ${ }^{2}$ \\ ${ }^{1}$ Department of Construction Engineering \& Technology, National Taiwan Institute of Technology, \\ Associate Professor, E-mail: myc @hp.ct.ntit.edu.tw \\ ${ }^{2}$ Department of Construction Engineering \& Technology, National Taiwan Institute of Technology, \\ Research Assistant
}

\begin{abstract}
This study focuses on developing an automated schedule monitoring system for precast building construction. Erection of prefabricated structural components is the major critical activity for the precast building construction. An efficient lifting schedule plan and control can significantly reduce construction conflicts and project delay. In this research, the system, ArcSched, was developed to assist construction managers to control and monitor the erection process in a real time base. ArcSched is composed of a Geographic Information System (GIS) integrated with a database management system (DBMS). Through systematic monitoring of the construction process and representing the erection progress in graphics and colors, the scheduled components for erection are repetitively tracked and well controlled to assure the lifting schedule as planned.
\end{abstract}

\section{Introduction}

Prefabrication of concrete structures is one of the most important advances made in the last decades towards industrialization of the building process. The construction sequence of precast building involves a close relationship between design, construction, detailing, execution, and manufacturing of elements. It is very difficult to obtain a successful project if the interrelationship between all the aspects of prefabrication is not understood by all engineers involved. In planning and design phases, designers have to design and divide the structural system considering the advantages of prefabrication, economic solutions and the reduction of construction time. The structural elements are prefabricated in the manufacturing plant and transported to the job site for installation. The schedules for prefabrication and transport of the structural elements to the job site are developed based on the construction installation schedule. Also, the storage and management of the prefabricated elements, installation sequence, schedule, and construction path planning should be well-planned before the construction commences. Fully consideration of constructability in planning, design, and manufacturing phases to improve construction efficiency can significantly effects the success of the precast building construction.

Erection of prefabricated structural components is the major critical activity for the precast building construction. An efficient lifting plan and control can reduce construction conflicts and project delay. Hence, the project managers should bear in mind the possibilities, restrictions, advantages and disadvantages of precasting, its detailing, manufacture, transport and erection and serviceability stages before developing a final construction installation plan on the basis of precast design. This study enhances the management and control of construction erection process by developing a real time schedule monitoring and control system. In the development of the system, industry rules of thumb and the state of the art in schedule control and monitoring were reviewed and compiled in a systematic form. Using the concept of distributed data collection and centralized management, an on-site control center is established for collecting and analyzing the construction information. The bar code system combining with the wireless radio transmit technology is applied to collect and transmit the job site data to the control center automatically. Through real time monitor of the construction process, the scheduled components for erection are repetitively tracked 
and well controlled to assure the lifting schedule as planned.

\subsection{Research objectives}

The primary purpose of this paper is to develop an automated schedule control and monitoring system for precast building construction. The objectives required to achieve the primary purpose are the followings: (1) apply bar code system integrating with radio frequency transmit technology to improve the efficiency of job site data collection, (2) develop an on-site control center provided with the real time schedule monitoring system to control and monitor the lifting operations, (3) identify the differences between the planned schedule and construction progress, (4) display the status of erection progress and sequence in graphics with different colors and labels, and (5) allow for graphical query of the detailed shop drawings and the related tabular attributes.

\subsection{Scope definition}

In this study, the system, ArcSched, was developed to assist construction managers to control and monitor the lifting process for precast building construction. With appropriate modifications, ArcSched can be applied to steel structure for controlling and monitoring the steel erection process.

\section{Construction Integration Using Automated Bar Code Identification System}

Construction integration is achieved by applying the automated bar code identification system in different phases of the precast construction life cycle. Bar code applications are implemented in three phases: (1) design, (2) manufacturing, and (3) construction erection. Through the application of the bar code system, the data integrity and consistency between different phases are ensured.

(1) design phase:

During the design phase, the structural components for prefabrication are analyzed and divided after detailed design layout and structural analysis are completed. According to the principle of the prefabricated element coding system, each prefabricated unit is assigned with a unique code. This code is the identification of the element which will be used for manufacturing, transport, storage, and construction installation.

(2) manufacturing phase

The structural components are produced in the plant based on the schedule of production. The bar code assigned for each element in the design phase is used for the creation of shop drawings, production schedule, and inventory control of the finished products in the storage yard.

(3) construction erection phase

Before the construction commences, managers have to prepare the installation schedule according to the construction plan and develop a lifting schedule database. The manufacturing and transport schedules are reconfirmed based on the installation schedule and feedback to the manufacturer as a reference for planning and revising the production plan. The consistency of information between manufacturing and construction phases can be assured. Through the identification of the bar code, the managers can record the prefabricated elements transported to the site, identify the storage area, and inquiry the erection sequence and schedule by using ArcSched installed in the main computer of the control center.

The process of integration through the application of bar code is shown in Fig 1.

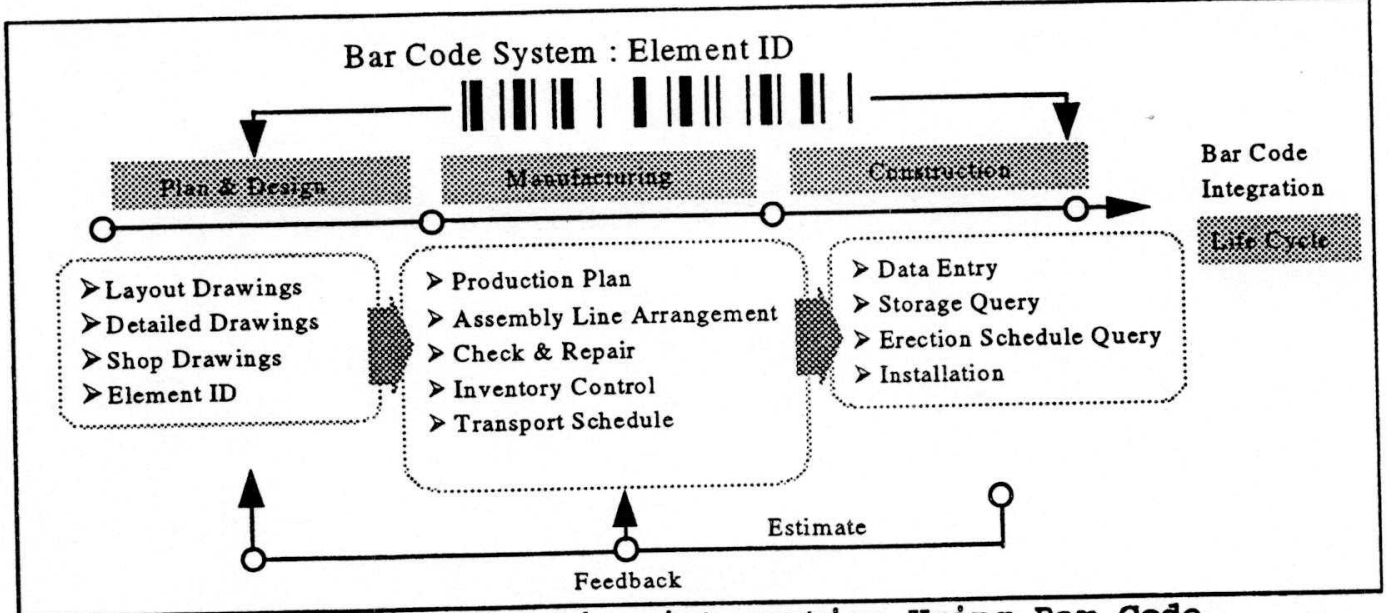

Figure 1 Construction integration Using Bar Code 


\section{Architecture of Schedule Monitoring and Control Process}

The architecture of schedule monitoring and control process is developed according the needs of the management of the erection process (Fig 2). The operational structure for job site scheduling control has four parts including: (1) wireless bar code transmit system, (2) on-site control center, (3) automated data collection using bar code collector, and (4) v8 video monitoring.

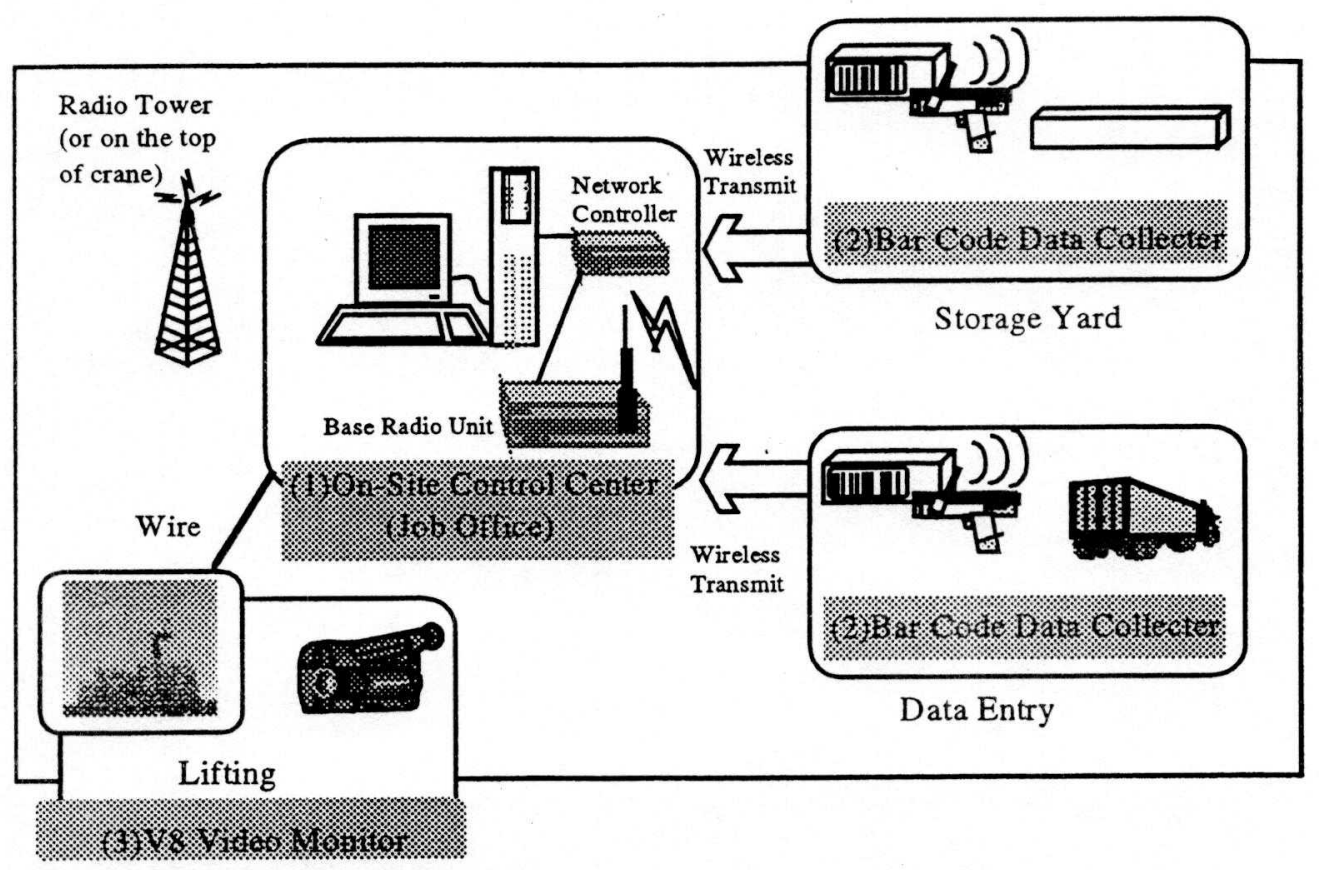

Figure 2 Operational Structure for On-Site Schedule Monitoring and Control

(1) Wireless bar code transmit system

The wireless bar code transmit system is a technology combining bar code system with radio frequency (RF) transmit technology. It is applied to collect and transmit the data generated on the job site to the control center. RF has primary applications in areas where environmental constraints prohibit the use of other automatic identification technologies. Especially for construction site, the places for gathering and entering data may change along with the progress of construction. Also, the working environment is sever and the area of the site always has a certain amount of scale. Thus, it is very suitable to apply RF technology to gather and transmit the job site data.

(2) on-site control center

The on-site control center is established in the job office. Using the concept of distributed data collection and centralized management, an on-site control center is established for collecting and analyzing the construction information. When the bar code of the prefabricated element is wirelessly transmitted to the center, the data is imported to the ArcSched database for later inquiry and analysis. As the central administration, the control center is used for bar code read/write, data import/export, data query, and schedule control. Through real time monitor of the construction process, the scheduled components for erection are repetitively tracked and well controlled to assure the lifting schedule as planned.

(3) automated data collection using bar code collector

The data collection efficiency is improved by using the automated bar code collector to gather and enter the job site data. There are two stages of using the wireless bar code transmit system to collect the bar code of the prefabricated unit: (a) job site entrance and (b) storage yard. When the prefabricated units are transported to the job site, the bar codes of the prefabricated units are read by the bar code collector at the entrance of the site. Through wireless RF transmission, the data is transmitted to the control center and saved in the associated database. To lift the units from the storage yard for installation, the bar codes of the units are also read and transmitted to the control center to check the related erection information such as position, sequence, and date.

(4) v8 video monitoring

V8 is installed on the top of the tower crane to monitor the installation process. With no need to go out 
the field, the project managers can monitor the erection process in the job site office. Also, the video tapes can be saved as construction records for the improvement of the erection process and training. Coaxial cable is the transmission media used to transmit the video image to the control center.

\section{System Development}

\subsection{System usage}

System usage essentially involves identifying the needs of the users. According to user's needs, the information flow for controlling the erection process is identified. The functional modules of the system are developed based on the information flow (Fig 3).

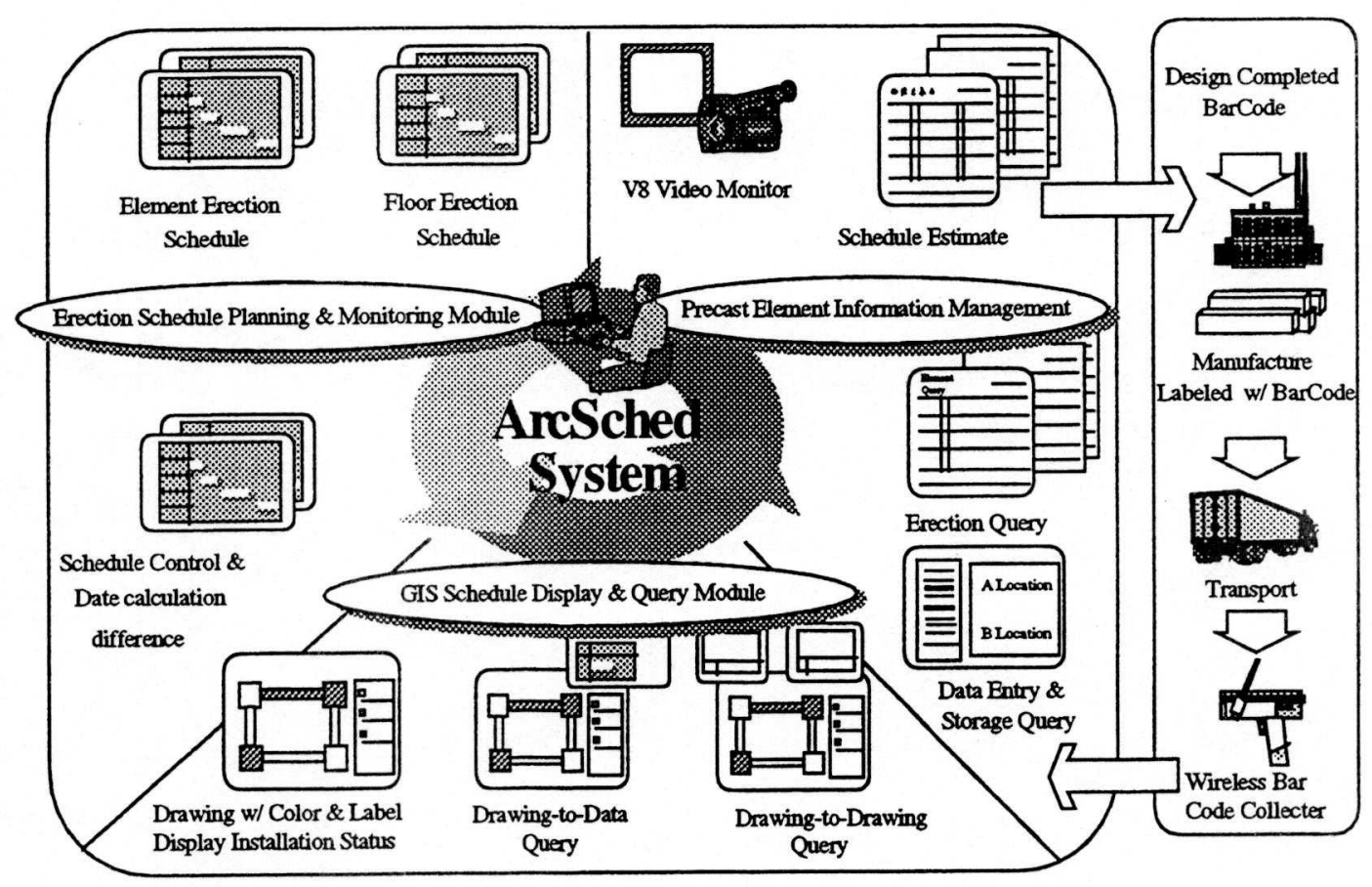

Figure 3 Information Flow for Schedule Monitoring and Control

\subsection{System architecture}

The architecture of the system involves identification of the tools used to develop the system functional modules and the means by which each will interface with one another and the user. Figure 4 shows the architecture of the system. The user and program interface for ArcSched is established at three levels: application user interface, command user interface, and program data interface.

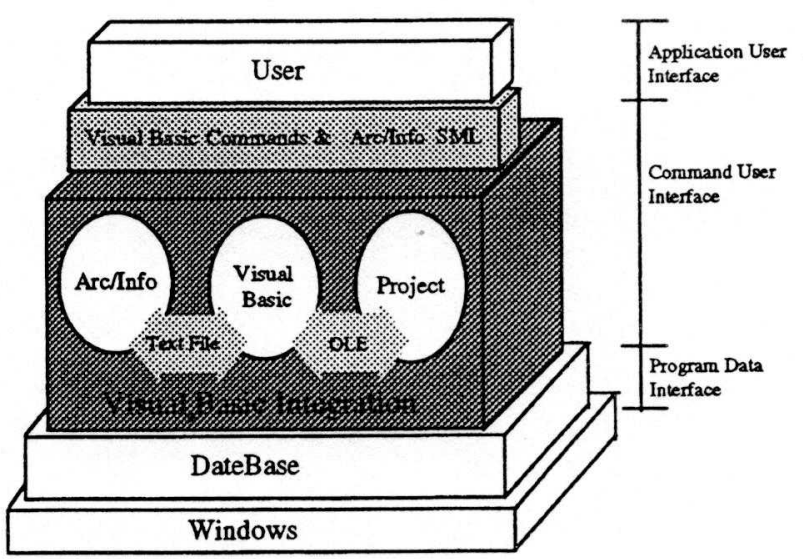

Figure 4 System Working Environment

The prime components of the system including Visual 
Basic, Arc/Info, and MS-Project are developed under Window environment. The user communicates with the components of the system, through a custom interface developed in Visual Basic. A set of the application user interface objects including pull down menus, pop up menus, and forms were developed for the system. In addition to automating the system design and directing the program flow of control, the command user interface is used to integrate the tools applied for the development of the functional modules. The program data interface writes/reads the information to/from the associated databases. In this way, the data file which are stored in a standard dBASE file format act as the communication media.

\subsection{System functions}

ArcSched is composed of a Geographic Information System (GIS) integrated with a database management system (DBMS). The system has three major modules including precast component information management module, erection schedule planning and control module, and GIS schedule display and query module (Fig 5). With the application of the Bar Code system and program data interface, the three functional modules are integrated by storing, retrieving, and managing the information to/from the associated databases.

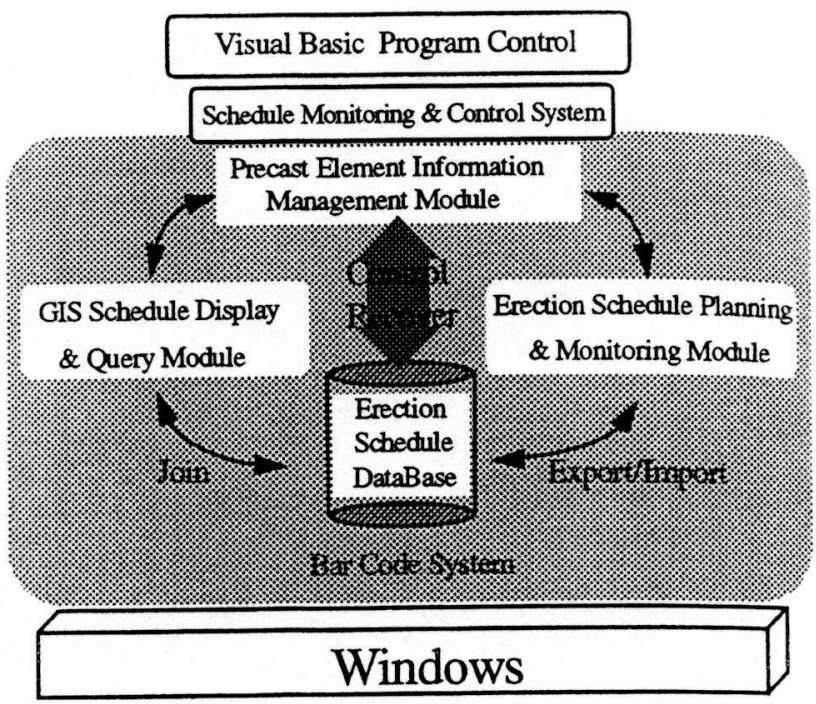

Figure 5 System Structure of the Functional Modules

(1) Precast unit information management module

The precast unit information management module is developed using Visual Basic. According to the capabilities and information needed for the user to conduct the construction installation, four major functions of the module are identified : (1) data entry and storage management (Fig 6), (2) V8 video monitor(Fig 7), (3) erection schedule query, and (4) schedule estimation (Fig 8 ). The management and maintenance of the erection schedule database is directly controlled by this module.

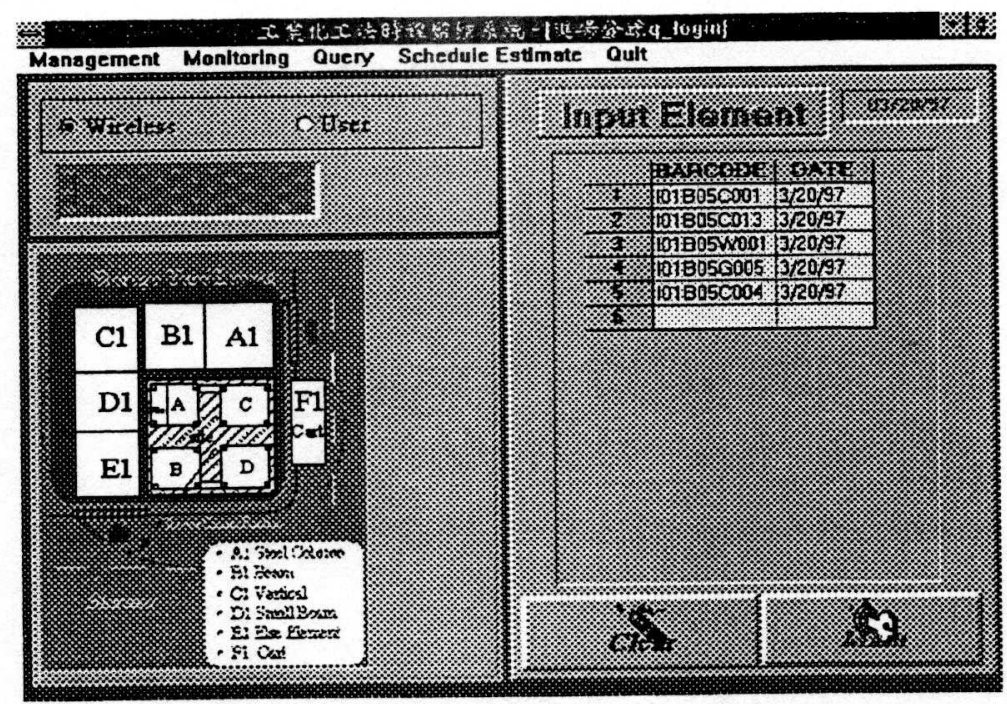

Figure 6 Data Entry Menu at Site Entrance 


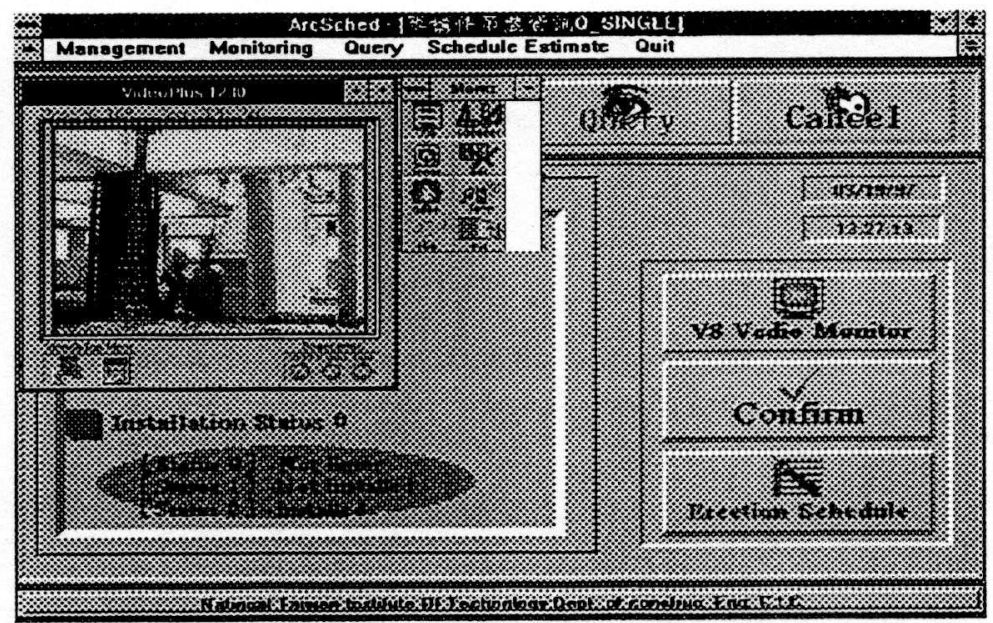

Figure 7 Real Time Erection Monitoring Menu

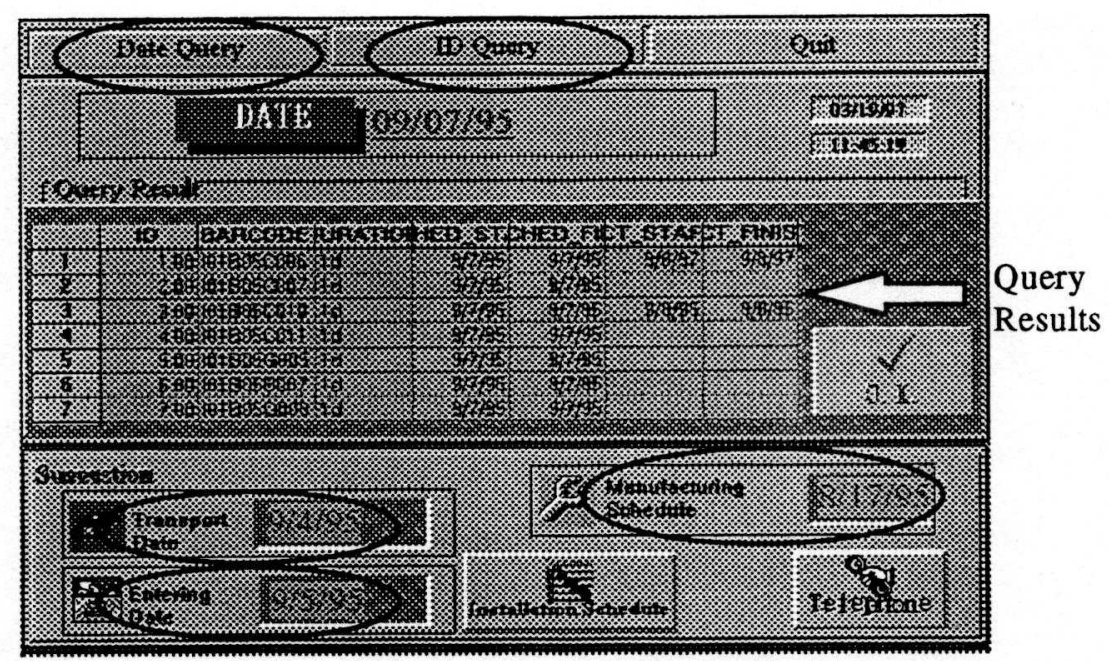

Figure 8 Schedule Estimate fir Transportation 
(2) Erection schedule planning and control module

MS-Project is the tool used to create and control the scheduling plan. To develop the erection plan, the quantity of the daily erections is calculated based on the constructability consideration ,construction plan, manufacturing plan, lifting capacity, and the categorizations of the precast units. This module allows the user to prepare the network of the erection sequence and formulate the logic of the contemplated program. Fig 9 shows the structure of the scheduling plan. The scheduling plan is classified in two levels: preliminary and detailed schedules. The functions of the module include: (1) network display, (2) activity selection, (3) progress update, and (4) duration calculation and difference analysis.

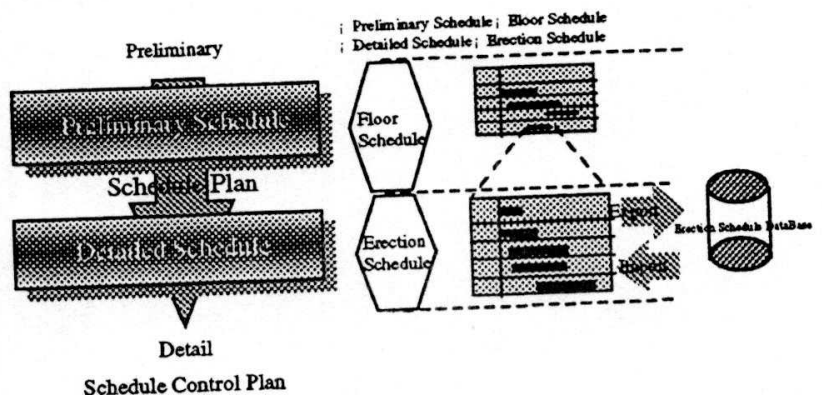

Figure 9 Erection Schedule Control Plan

(3) GIS schedule display and query module

The graphical display and query is carried out using the GIS Arc/Info functional modules such as Starter Kit, Arcplot, and Tables. The primary functions of this module are described as follows: (1) graphic file management: allow the user to access, retrieve, delete, display, and manipulate the related graphic files, (2) design drawing display: display the design drawings along with the erection sequence and position represented in labels (Fig 10), (3) "drawing-to-data" query: allow for graphical query of the related tabular attributes such as erection sequence, position, and schedule (Fig 11), (4) "drawing-to-drawing" query: allow for graphical query of the detailed shop drawings (Fig 12), and (5) graphical display of erection progress: display the status of erection progress in graphics with different color (Table 1). As the installation of the prefabricated unit is completed and confirmed by the user through the v8 monitoring, the color of the associated graphic feature is changed to reflect the lifting progress. Nevertheless, the Video tape can be saved as construction records for training. The erection progress can not only be controlled by the construction mangers through directly graphical display and query of the drawings, but also the erection accuracy and efficiency are insured.

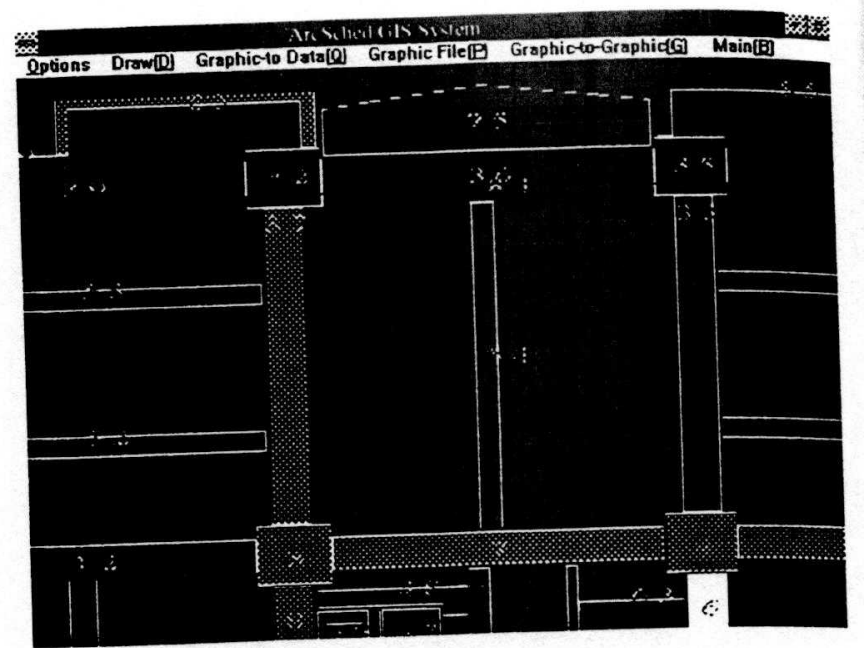

Figure 10 Design Drawing Erection Sequence Display

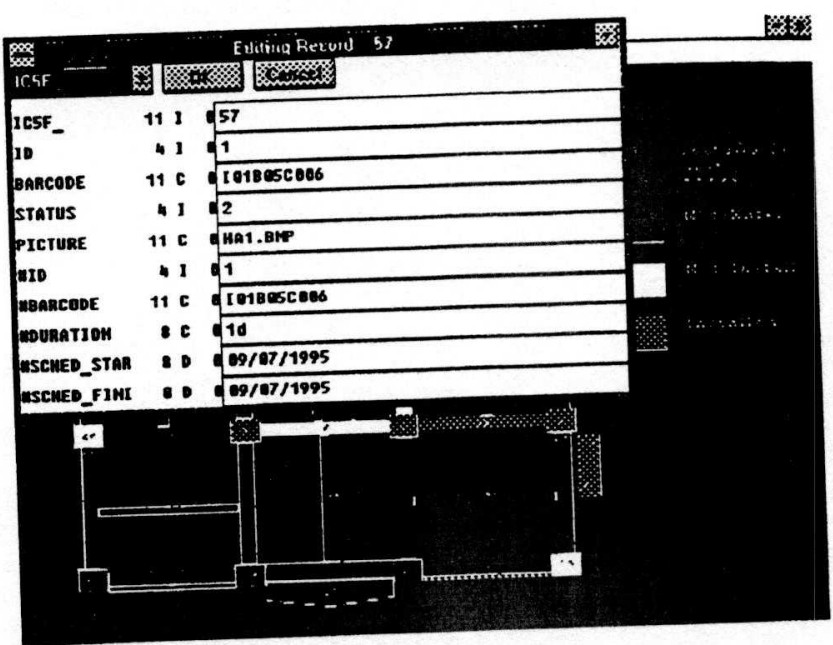

Figure 11 Drawing-to-Data Query

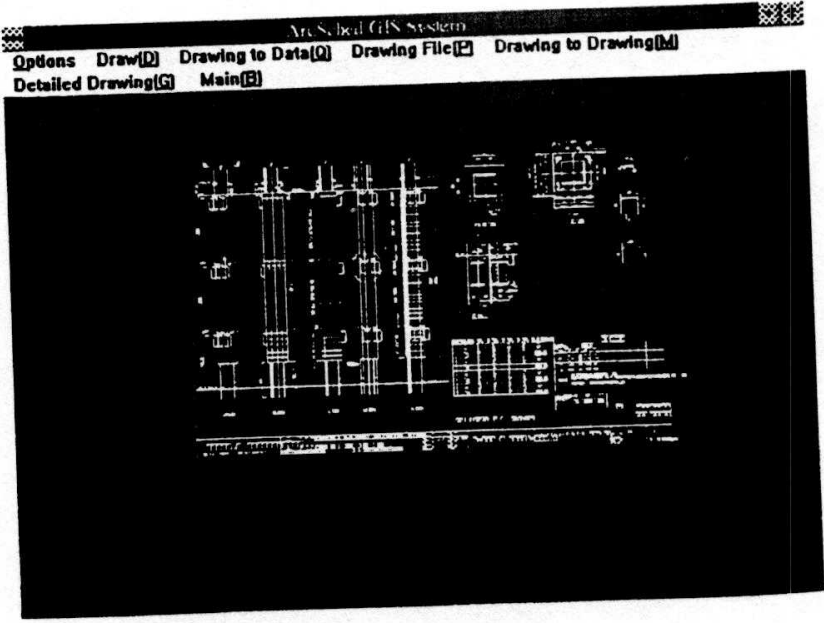

Figure 12 Drawing-to-Drawing Query 
Table 1 Control Status of Prefabricated Units

\begin{tabular}{|l|l|l|}
\hline Element Color & \multicolumn{1}{|c|}{ Control Status } & GIS Code \\
\hline black & not delivered & code "0" \\
\hline white & not installed & code "1" \\
\hline red & installed & code "2" \\
\hline
\end{tabular}

\section{Conclusions and Recommendations}

The endeavor of this paper focuses on developing an automated schedule monitoring system to assist the managers to control the erection process for precast building construction. ArcSched improves the data collection efficiency by the integration of bar code system with the wireless RF transmit technology. The development of the computer integrated construction system successfully improves the efficiency of the lifting operations for percast building construction. Also, the integration of schedule and design information makes it easy for the project manager to monitor and control the erection progress. Owing to Arc/Info's ability to integrate locational and thematic information, the graphical display and database queries including graphic file management, design drawing display, drawing-to-data query, drawingto-drawing query, and graphical display of erection progress are achieved. Compared with current methods, this paper creates a new way of thinking to represent construction progress in graphics using GIS.
ArcSched improves the schedule control efficiency by integrating spatial and thematic information into a single environment. The application of the real time schedule monitoring system can not only improve the construction constructability, but the construction efficiency can also be increased.

\section{References}

1. Liou, F.S., "Keyless Data Acquisition in Construction", Architectural Science Review, U.S.A., pp. 9-16, 1992.

2. Rasdorf, W.J. and Herbert, Mark J., "Bar Coding in Construction Engineering", J. Constr. Eng. and MGMT., ASCE, Vol. 116, No. 2, pp. 261-280, 1990.

3. Interscan User's Manual, INTERMEC, Washington, U.S.A., 1994.

4. Bell, Lansford C. and Bob G. McCullouch, "Bar Code Applications in Construction", Source Document No. 33, Construction Industry Institute, Austin, Texas, 1988.

5. Stukhart G and Cook E. L., "Bar Code Standardization in Industry Construction", Source Document No. 47, Construction Industry Institute, Austin, Texas, 1989.

6. Tatum C.B., Vanegas J.A., and Williams J.M., "Constructability Improvement Using Prefabrication, Preassembly, and Modulization", Source Document No. 25, Construction Industry Institute, Austin, Texas, 1987.

7. Bruggeling A.S.G. and Huyghe G.F., Prefabrication with Concrete, Balkema Publishers, Brookfield, U.S.A., 1991.

8. Whitaker J.C., Radio Frequency Transmission Systems, McGraw-Hill, Inc., 1991. 